\title{
The use of screening of crushed granite stone for the production of building materials
}

\author{
Fedor Gorbunov ${ }^{1,2-}$, Lilia Berdnikova ${ }^{1}$, Victor Bulgakov ${ }^{1}$, Alexandra Fadina $^{1}$, and Andrey \\ Lapin $^{2}$ \\ ${ }^{1}$ Institute of Solid State Chemistry and Mechanochemistry of SB RAS, 630128, 18, Kutateladze str., \\ Novosibirsk, Russia \\ ${ }^{2}$ Novosibirsk State Technical University, 630073, 20, K. Marx Ave., Novosibirsk, Russia
}

\begin{abstract}
The possibility of using technogenic raw materials - the screening of crushed stone with the addition of cullet based on a silicate binder for the production of construction materials for structural purposes is studied. By varying the processing temperature, it was possible to increase the softening coefficient of the products and to achieve the $\mathrm{pH}$ neutrality of their pore liquid. Products processed at a temperature of 500$700{ }^{\circ} \mathrm{C}$ have the following performance characteristics: the compressive strength 16.6-31.4 MPa, the bending strength 3.4-5.9 MPa.
\end{abstract}

\section{Introduction}

The main problem of crushed stone production during the crushing of rocks is the resulting secondary screenings of various sizes, which relate to the waste of this industry. The repeated use of such dropouts does not exceed $2-4 \%$ of their formation per year [1]. Today, the screening of crushed stone can be a valuable construction raw material with a low cost, the use of which will reduce the cost of final products and rational use of natural resources.

One of the most common types of screenings is granite screenings, obtained in the production of crushed granite. It has high performance characteristics that allow it to be used in any construction work $[2,3]$.

The purpose of the work is to develop a method for obtaining construction products based on granite screenings of crushed stone and silicate binder.

\section{Experimental}

As a filler for obtaining samples, we used polyfraction $(0.14-7 \mathrm{~mm})$ of the granite screenings of crushed stone from the Borok quarry in the city of Novosibirsk. Cullet with a grain size (d) of $<0.14 \mathrm{~mm}$ was used as the additive.

Sodium hydroxide, water, and diatomite of the Inzenskoye deposit, previously fired at $900{ }^{\circ} \mathrm{C}$, were used as raw materials for obtaining a binder with a different silicate module.

- Corresponding author: f1123723@yandex.ru 
The heat-treated diatomite contained (\%) 84.8 $\mathrm{SiO}_{2}, 7.7 \mathrm{Fe}_{2} \mathrm{O}_{3}, 3.9 \mathrm{Al} 2 \mathrm{O} 3,3.1 \mathrm{~K}_{2} \mathrm{O}$, and $0.5 \mathrm{MgO}$.

The synthesis of the binder with the silicate module (M) 2 and 3 was carried out by mixing the diatomite with a grain size of less than $0.5 \mathrm{~mm}$ with a $20 \%$ solution of sodium hydroxide in the ratio $\mathrm{S}: \mathrm{L}-1: 4$ and $1: 3$ parts by weight, respectively, followed by the heat treatment of the mixture at $100{ }^{\circ} \mathrm{C}$ for 16 hours with periodic stirring.

Separation of the sediment that did not react with the alkali solution was carried out by precipitation. Filtrate was used as a binder, the yield of which was $\sim 60 \%$ and $40 \%$ for silicate module 2 and 3, respectively. The samples were obtained by vibration casting. To do this, a homogeneous mixture of the filler and binder was placed in molds and put on a vibrating table for 5 minutes. 24 hours later, the samples were removed from the molds and heat-treated at $50-900{ }^{\circ} \mathrm{C}$.

\section{Results and discussion}

It is known [4] that the solubility of solid substances directly depends on the size of their particles. In this regard, at the first stage of the work, the granulometric composition of the diatomite after heat treatment at $900{ }^{\circ} \mathrm{C}$ was studied (Fig. 1). It was found that the particle size of the heat-treated diatomite does not exceed 100 microns, which indicates their high specific surface area and chemical activity relative to the alkaline component.

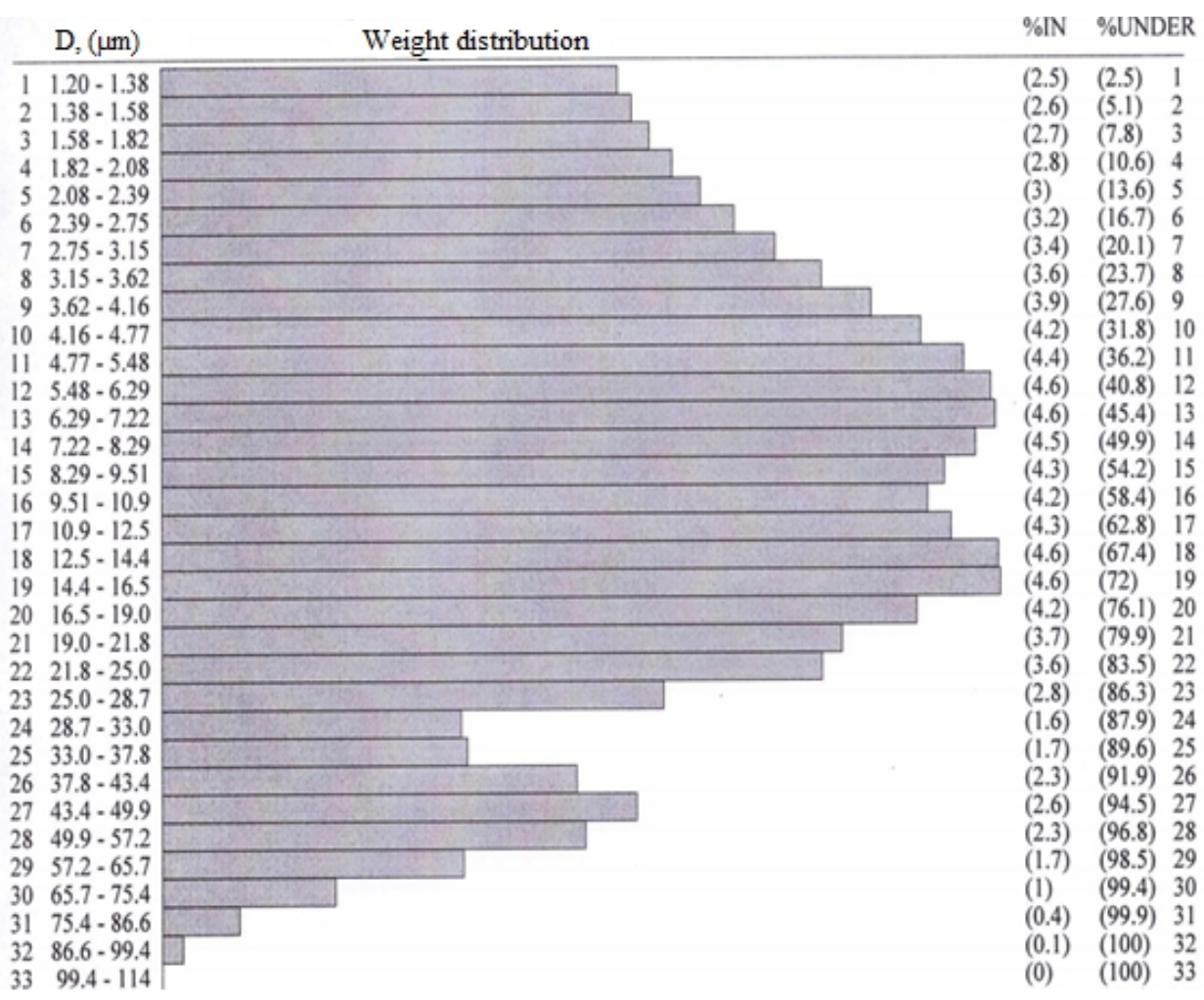

Fig. 1. Weight distribution of calcined diatomite particles depending on their size.

The use of any binder for obtaining construction products with specified characteristics, first of all, implies the selection of the quantity and ratio of the initial components [5]. 
Therefore, the second stage of this work was to search for a filler to binder optimal ratio (F:B) with silicate module 2 .

The highest strength, uniformity and workability of the molding mixture were selected as the criteria for evaluation of the manufactured samples. The as-prepared samples were heated at $50{ }^{\circ} \mathrm{C}$ until constant mass was achieved. The physical and mechanical characteristics of the samples are listed in Table 1. When preparing the construction product samples, quarry sand and scrap of the chamotte refractory (chamotte), pre-crushed to a fraction of $\leq 0.14 \mathrm{~mm}$, were used as the fillers. Their chemical composition is presented in Table 1.

Table 1. Characteristics of the binder-based samples $(M=2)$ depending on the $F: B$ ratio.

\begin{tabular}{|c|c|c|c|}
\hline \multirow{2}{*}{ F:B, parts by weight } & \multirow{2}{*}{ Density, $\mathbf{g} / \mathbf{c m}^{3}$} & \multicolumn{2}{|c|}{ Ultimate strength, MPa } \\
\cline { 3 - 4 } & & bending & compressive \\
\hline $4.0: 1$ & 2.06 & 4.3 & 8.2 \\
\hline $5.4: 1$ & 2.00 & 4.5 & 13.3 \\
\hline $9.0: 1$ & 1.81 & 4.2 & 8.8 \\
\hline
\end{tabular}

At a $F: B$ ratio of $4.0: 1$, the solidification time of the sample was more than a day. Also, in the process of the initial mixture formation, an excess of the binder appeared. Consequently, the samples at this ratio were not further tested.

At F:B weight ratios of $9.0: 1$ and $5.4: 1$, the resulting products have the following strength indicators: 4.2 and 4.5 $\mathrm{MPa}$ when bending; 8.8 and $13.3 \mathrm{MPa}$ when compressing, respectively. At the same time, the molding mass at a $\mathrm{F}: \mathrm{B}$ weight ratio of $9.0: 1$, has the poorer workability due to the higher content of the filler.

Analyzing the data given in Table 1, we can conclude that the products based on the binder with the silicate module 2 at a F:B ratio of 5.4:1 have the best physical and mechanical properties. At this ratio, the resulting products have the most homogeneous bound structure and high strength indicators. For further studies, the F:B ratio 5.4:1 was used to manufacture samples.

At the third stage of the work, the physical and mechanical properties of the samples obtained on a silicate binder with module 2 were investigated. At this stage, the effect of the heat treatment conditions on the sample's strength, water resistance and $\mathrm{pH}$ of the pore liquid has been studied (Table 2).

Table 2. Characteristics of the binder-based products $(M=3)$ depending on the heat treatment conditions.

\begin{tabular}{|c|c|c|c|c|c|}
\hline \multirow{2}{*}{ № } & \multicolumn{2}{|c|}{ Ultimate strength, MPa } & \multirow{2}{*}{$\begin{array}{c}\text { Water } \\
\text { absorption, } \%\end{array}$} & $\begin{array}{c}\text { Processing } \\
\text { temperature, }{ }^{\mathbf{}} \mathbf{C}\end{array}$ & $\begin{array}{c}\text { Softening } \\
\text { coefficient }\end{array}$ \\
\hline 1 & 10.9 & 22.4 & 5.4 & 50 & 0.12 \\
\hline 2 & 4.4 & 15.0 & 5.8 & 200 & 0.43 \\
\hline 3 & 4.6 & 17.4 & 5.4 & 300 & 0.55 \\
\hline 4 & 3.8 & 16.9 & 5.8 & 400 & 0.55 \\
\hline 5 & 2.0 & 9.8 & 7.8 & 500 & 0.80 \\
\hline 6 & 2.3 & 9.9 & 7.7 & 600 & 0.95 \\
\hline 7 & 2.5 & 10.6 & 6.8 & 700 & 0.93 \\
\hline 8 & 2.5 & 11.8 & 7.6 & 800 & 0.93 \\
\hline 9 & 3.2 & 13.7 & 7.5 & 900 & 0.98 \\
\hline
\end{tabular}


Based on the data obtained, it can be seen that the samples treated at a temperature above $50{ }^{\circ} \mathrm{C}$ lose their strength characteristics.

In turn, the water resistance of the samples is achieved at a processing temperature of $500{ }^{\circ} \mathrm{C}$ and above (the softening coefficient is $0.8-0.98$ ). It was found that at a processing temperature of $600-700{ }^{\circ} \mathrm{C}$, the volume of products increases by $2.1 \%$, while an increase in the processing temperature to $800{ }^{\circ} \mathrm{C}$ and above leads to their melting. The water absorption of the products ranged from $5.4 \%$ to $7.8 \%$ over the whole temperature range.

The analysis of the data obtained showed that the samples based on the binder with the silicate module 3 during heat treatment from 500 to $700{ }^{\circ} \mathrm{C}$ have the following strength characteristics: bending strength - 2.0-2.5 $\mathrm{MPa}$; compression strength - 9.8-10.6 $\mathrm{MPa}$. In this case, the pore liquid of the samples has a $\mathrm{pH}$ of over 7.

To lower the $\mathrm{pH}$ of the pore liquid, at the fourth stage of the work, a cullet of the fraction $\mathrm{d}<0.14 \mathrm{~mm}$ in the amount of $10 \%$ of the total mass of the molding mixture was used. The characteristics of the samples so-prepared are listed in Table 3.

Table 3. Characteristics of the products based on binder $(M=3)$, cullet and dropout, depending on the conditions of heat treatment.

\begin{tabular}{|c|c|c|c|c|c|}
\hline \multirow[t]{2}{*}{ № } & \multicolumn{2}{|c|}{$\begin{array}{c}\text { Ultimate strength, } \\
\mathrm{MPa}\end{array}$} & \multirow{2}{*}{$\begin{array}{c}\text { Water } \\
\text { absorption, \% }\end{array}$} & \multirow{2}{*}{$\begin{array}{c}\text { Processing } \\
\text { temperature, }{ }^{\circ} \mathrm{C}\end{array}$} & \multirow{2}{*}{$\begin{array}{c}\text { Softening } \\
\text { coefficient }\end{array}$} \\
\hline & bending & compressive & & & \\
\hline 1 & 7.2 & 35.3 & 2.4 & 84 & 0.32 \\
\hline 2 & 7.3 & 31.2 & 5.3 & 49 & 0.69 \\
\hline 3 & 6.1 & 34.1 & 4.9 & $8 \times$ & 0.62 \\
\hline 4 & 3.2 & 26.7 & 5.3 & 6 & 0.93 \\
\hline 5 & 3.4 & 31.4 & 5.5 & $80 \%$ & 0.80 \\
\hline 6 & 5.9 & 25.5 & 6.5 & 6061 & 0.81 \\
\hline 7 & 5.7 & 16.6 & 6.3 & 700 & 0.96 \\
\hline 8 & 6.7 & 19.6 & 6.7 & 868 & 0.75 \\
\hline 9 & 3.2 & 11.8 & 11.5 & 960 & 0.33 \\
\hline
\end{tabular}

$\mathrm{pH}$ of the pore fluid

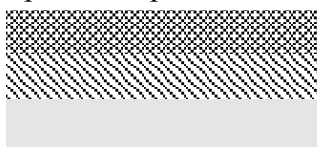

\section{Highly alkaline \\ Slightly alkaline \\ Neutral}

It was found that the addition of the cullet leads to a decrease in the heat resistance of the samples. Thus, at $600{ }^{\circ} \mathrm{C}$, an increase in the product volume by $13 \%$ is observed. At 900 ${ }^{\circ} \mathrm{C}$, the samples are melted, which leads to an increase in their volume by more than $50 \%$.

However, the samples treated at a temperature of $400-700{ }^{\circ} \mathrm{C}$ are water resistant (softening factor is $0.80-0.96$ ). A neutral $\mathrm{pH}$ of the pore fluid can be achieved when treating the sample at $700{ }^{\circ} \mathrm{C}$. Therefore, the optimal temperature range resulting in an increase in the water resistance and neutral $\mathrm{pH}$ of the pore liquid is considered to be $500-700{ }^{\circ} \mathrm{C}$. The compressive and flexural strength of the samples in this case are 16.6-31.4 MPa and 3.4-5.9 $\mathrm{MPa}$, respectively.

The comparative characteristics with traditional materials given in Table 4 may indicate the prospect of using granite screenings as filler for the production of construction products. 
Table 4. Comparative characteristics of the construction products [6, 7].

\begin{tabular}{|c|c|c|}
\hline \multirow{2}{*}{$\begin{array}{c}\text { Construction products } \\
\text { (GOST 530-2012) }\end{array}$} & bending & compressive \\
\cline { 2 - 3 } & $9.6-28.9$ & - \\
\hline $\begin{array}{c}\text { Concrete M100-M300 (GOST 26633-91) } \\
\text { (GOST }\end{array}$ & $10.0-30.0$ & $2.2-4.4$ \\
\hline Ordinary ceramic brick M100-M300 & $16.6-31.4$ & $3.4-5.9$ \\
\hline
\end{tabular}

* Samples based on the binder with a silicate module 3 and treated at $500-700{ }^{\circ} \mathrm{C}$.

\section{Conclusions}

A method to fabricate building materials based on the waste of crushing granite rubble, cullet and silicate binder has been developed.

It was found that when heating from 500 to $700{ }^{\circ} \mathrm{C}$, the water resistance of the products increased and a neutral $\mathrm{pH}$ of their pore liquid was achieved.

The physical and mechanical parameters (the compressive strength 16.6-31.4 MPa and the bending strength 3.4-5.9 $\mathrm{MPa}$ ) of the developed materials are comparable with those of the traditional materials, which suggests the prospect of using granite screenings as the filler for the production of construction materials.

This work was supported by the Ministry of Science and Higher Education of the Russian Federation within the governmental order for Institute of Solid State Chemistry and Mechanochemistry of SB RAS (project(s) FWUS-2021-0004).

\section{References}

1. A.V. Genkel, I. A. Grishin, K.V. Burmistrov, V.S. Velikanov, Mining Industry, 6, 124 (2015)

2. GOST 31424-2010. Non-metallic construction materials from the screenings of crushing dense rocks in the production of crushed stone. Technical conditions (Moscow, Russia, 2010)

3. Project of organization of recycling (utilization) of construction waste at the crushing and sorting complex DSK-48-13, scientific and production enterprise Obukhovskaya industrial company, Nizhny Novgorod, (2019)

4. Yu.V. Khodakov, General and inorganic chemistry (Moscow, USSR, 1959)

5. L.R. Vishnyakov, TV. Grudina, V.Kh. Kadyrov, Composite materials (Kiev, USSR, 1985)

6. GOST 26633-91. Heavy and fine-grained concrete. Technical conditions (Moscow, Russia, 2005)

7. GOST 530-2012. Ceramic brick and stone. General specifications (Moscow, Russia, 2012) 